\title{
Deficiência, saúde pública e justiça social
}

\section{O que é deficiência?}

DINIZ, Débora.

São Paulo: Brasiliense, 2007. 96 p. (C oleção Primeiros Passos).

Durante um longo período, deficiência fol sinônimo de desvantagem natural. Os saberes biomédicos dominaram o campo dos estudos sobre deficiência. A obra O que é deficiência, da antropóloga Debora Diniz, publicada na Coleção Primeiros Passos, é uma provocação à compreensão biomédica da deficiência como desvantagem biológica. A vida de Jorge Luis Borges, escritor argentino cego, é o tropo inicial da obra que assume a assertiva de que "...ser cego é a penas uma das muitas formas corpora is de estar no mundo..." (p. 7-8). Essa redescrição da deficiência em temos sociológic os revela que a lesão é algo recorrente no ciclo da vida humana, especialmente em razão do envelhecimento populacional. Com isso, a pesquisadora mostra que a deficiência é um conceito complexo que, além de reconhecero corpo com lesão, denuncia a estrutura social que aparta do convívio social a pessoa deficiente. A narrativa é um convite à reflexão; uma provocação ao autismo social e govemamental a diante da emergência da diversida de de estilos de vida.

O livro é dividido em cinco partes que abordam os seguintes assuntos: o modelo social da deficiência; a revisão do modelo médico; e a deficiência, feminismo e cuidado. Um aspecto preliminar na narrativa é a oposição à idéia de deficiência como anormalidade. Segundo a autora, a deficiência não é uma variação do normal da espécie humana, pois a nomalidade é um julgamento estético e, portanto, um valor moral sobre estilo de vida. Essa foi uma crítica central para a construção da primeira geração do modelo social da deficiência. É que a anomalidade era um argumento recorrente para explicar o encarceramento de pessoas com lesões físic as e menta is severas. Antes do modelo social, essas pessoas sobreviviam isoladas em instituições que, a pretexto de tratá-las para devolvê-las à família ou à sociedade em condições de nomalidade, impunham-lhes um regime de alienação moral baseado no a utoritarismo e na crueldade. O objetivo do modelo social, um marco teórico nos estudos sobre deficiência, era ir além da medicalização daslesões.

A desconstrução da imagem do defic iente como uma pessoa anomal lastreou a tese da Liga dos Lesados Físic os contra a Segregação (Upias), a primeira organização formada e gerenciada por deficientes na história da civilização. A Upias defendia que a exclusão social que vitimava os deficientes não decomia de suas limitações corpora is, como entendia a medicina. Segundo a Upias, a deficiência decorria do desamparo institucionalizado de organizações socia is e polític as pouco sensíveis à diversida de corporal. Sem dúvida, essa foi uma estratégia decisiva, porque, ao tempo em que aproximava os deficientes de outras minorias, como as mulheres e os negros, também legitimava a reivindicação de que a deficiência 
deveria ser, por isso mesmo, matéria de ações polític a sa firma tiva s e de intervenção do Esta do. Mesmo sendo inicia Imente um movimento social enviesado pelo maior destaque à deficiência física, a Upias conseguiu demonstrar que, independentemente da forma de deficiência, ela sempre implica va uma experiência de opressão.

A inovação do modelo social de deficiência estava na concepção de que a experiência da opressão não é uma conseqüência natural de um corpo com lesões. Seria, na verdade, uma imposição social. O problema é que, como demonstra a autora, diferentemente das discussões sobre desigualdade de gênero, nas qua is há consenso político de que a biologia não determina a desvantagem social, no campo da deficiência esse seria um argumento inócuo: a rejeição à lesão é algo tão difundido nas sociedades industria lizadas que a separação entre a natureza e a sociedade não seria facilmente digerida nasnegociações polític as em prol dos direitos dos defic ientes. Com base nisso, houve a primeira releitura do modelo social tal como ele foi concebido. A crítica buscava trazer o corpo para o centro dos debates sobre justiça para os deficientes. Como espaço de expressão da desigualdade, o corpo não devia ser ignorado, inclusive porque nem todos os ajustes a rquitetônicos possíveis garantirão a plena liberdade de ir, de vir e de agir das pessoas deficientes, cujas demandas variam de acordo com a multiplicidade e a gravidade de suas lesões, motoras e/ou cognitivas.

Maso enfoque no corpo não signific ou um a traso a os estudos sobre deficiência. Muito pelo contrário. O corpo é um aspecto central no debate sobre deficiência, especialmente porque pessoas produtiva s podem, a pós longos a nos de trabalho mecânic o, experimentara deficiência. Ou seja, a deficiência não é apenas fruto do acaso da natureza. Não deve ser vista como problema individual, fruto de tragédia pessoal ou de uma limitação corporal. Uma prova disso são os idosos, que experimentam a deficiência pelo desgaste gradual do corpo. Nesse ponto, Diniz mostra o quanto a inclusão dosidosos no universo da deficiência representou uma guinada a rgumenta tiva a o debate. A visão da deficiência como um problema social, sem negligenciamento $d a$ representatividade do corpo, repercutiria de modo positivo na implementação de políticas de saúde pública e direitos huma nos, com priorida de às medidas de reparação de desigualdade, e não às medidas sa nitá rias de reabilita ção. Uma conquista paradigmática.
Um capítulo fundamental para a compreensão da evolução dos estudos sobre o tema é o que aborda a revisão do modelo médico, em que Diniz analisa a importância e a tensão decorrente da public a ção, em 1980, pela Organização Mundial de Saúde (OMS), de um catálogo oficial de lesões e deficiências semelhante à Classificação Internacional de Doenças (CID): a Classific ação Internacional de Lesão, Deficiência e Handicap (ICIDH), cujo caráter teleológico era, para a lém da unific a ção da terminologia sobre a linguagem biomédica sobre lesões e deficiências, principalmente propiciar uma padronização para fins comparativos e de políticas de saúde. O novo vocabulário proposto pela OMS representou, no entanto, retrocesso ao debate sobre deficiência, porque resgatou conceitos pemiciosos, como o de a normalidade, a o debate. O impacto de um vocabulário elaborado pela OMS, cuja força política no cenário intemacional é indiscutível, pôs em risco as conquistas feitas pelos teóricos do modelo social da deficiência.

No entanto, a publicação da ICIDH teve uma influência positiva para o debate, porque foi o pontapé inicial para uma grande fase de crescimento intelectual para o modelo social, que, numa tentativa concertada de impedir o revigoramento do modelo médico, procurou demonstrar a fragilidade da ICIDH para o enfrentamento da questão política da deficiência. As novas críticas minaram a força da ICIDH. A ICIDH parecia uma expansão da CID, um a specto negativo do documento, porque aproximava a deficiência das doenças, o que afastava o debate do campo sociológico. Com isso, os críticos mostraram que a ICIDH implicava uma maneira ca mufla da de retomara medica liza ção sobre o corpo com lesões. No mais, a ICIDH carecia de representatividade, porque havia sido feita por pessoas sem experiência pessoal na defic iência, a lém de lastrear-se em concepções de nomalidade para a pessoa humana. A revisão da ICIDH ocorreu na década de 1990 e, dessa vez, contou com intensa partic ipação de diversas entidades a cadêmicas e de movimentos socia is de deficientes.

A revisão teve por desfecho a publicação da Classificação Internacional de Funcionalidade, Deficiência e Saúde (CIF), em 2001. Com ela, a defic iência deixou de sermera conseqüência de doenças para se tomar uma questão pertencente aos domínios da saúde, traduzindo-se numa tentativa de integrar os modelos médico e social de deficiência. A public ação da CIF foi um marco nosestudosque, 
porém, ainda sofreram críticas. Outra crítica importante adveio da perspectiva feminista, que deu origem à segunda geração de teóric os do modelo social de deficiência. A revisão do modelo social da deficiência à luz do feminismo desestabilizou a falsa suposição de que os deficientes, sem exc eção, retira das as ba rreiras físicas, prescidem de a uxílio ou a poio de terceiros para conduzir os rumos da própria vida. 0 que as teóric as feministas queriam era mostrar que o c uidado também é uma demanda de justiça social dos defic ientes. Era preciso assimilara idéia de que a independência não deve serum valor c entral do modelo social, ou seja, as relações de dependência são inevitáveis à vida social; são inescapáveis à história de vida de todas as pessoas.

A crítica feminista causou uma revolução nos estudos sobre o tema da deficiência. Como esclarece a autora, a perspectiva feminista tinha por principal desafio demonstrar a possibilidade de haverum projeto de justiça que considerasse - cuidado em situações de extrema desigualdade de poder, sem que isso implic asse devolver os deficientes ao espaço de subaltemida de e de exc lusã o social. Mas a crític a feminista, segundo Diniz, não era somente uma proposta de mudança de paradigma. Havia uma estratégia perspicaz por detrás dela: numa sociedade pouco sensível aos interesses dos defic ientes, seria ma isfácil ga rantiro cuida do que modific ara ordem sociale polític a que osoprimia. Nesse ponto, a os olhos dos primeiros teóric os do modelo social, a crítica feminista implicava, inic ia Imente, uma a meaça política. Com o passar do tempo, não houve outra saída senão reconhecer que, além da perspectiva dos deficientes, era preciso levar em consideração também o ponto de vista das cuidadoras dos defic ientes.

Nisso, a crítica feminista outra vez sumreendeu, porque viabilizou o reconhecimento de outra autorida de sobre a deficiência que não apenas o deficiente \% algo inquietante para a primeira geração de teóricos do modelo social, porque abalou o argumento de autoridade de que era preciso serdeficiente para escreversobre deficiência. A figura da cuidadora foi colocada no centro do debate sobre justiça e defic iência denunciando o viés de gênero no liberalismo polític o e servindo, sobretudo, como a lerta para o fato de que há desigualdades de poder no campo da defic iência que ja ma is serão resolvidas porajustes arquitetônic os. A crític a feminista teve o papel fundamental de desvelar outros protagonistas do universo da deficiência, que vivenciam a experiência da deficiência pelo cuidado aos filhos, sobrinhos, pais, parentes e pessoas com quem não têm vínculo familiar, como é o caso de enfermeiros. Com a crítica feminista, o debate sobre a defic iência passou a considerarque a absoluta independência é uma bandeira perversa que certamente implicará desa mparo a os defic ientes.

A deficiência é um tema extremamente delicado. 0 livro de Diniz propicia a compreensão de que a deficiência resulta de um relacionamento complexo entre as condições de saúde de um indivíduo e os fatores pessoa is e extemos, sendo um conceito guarda-chuva que associa a concepção médica de lesão aos aspectos negativos da interação entre o sujeito e o contexto social. Um aspecto que merece destaque no livro é a profundidade da abordagem, que, apesar de ter sido publicada numa coleção editorial com um perfil didático para leitores leigos, não omitiu dados nem conceitos relevantes para a compreensão fidedigna do tema. Para a lém da importância acadêmica da obra, o livro representa uma chamada de justiça social, pois nunca, na história da civilização humana, tantas foram as demandas de respeito a os direitos humanos, que passaram a ser, por essa razão, o vértice das ações govema menta is dos países democ rátic os. Os desafios sobre o tema a inda são muitos, mas o entendimento de que a deficiência é uma exp ressão da diversida de de estilos de vida é um a vanço sem precedentes para a concretização de um projeto de justiça social urgente: a integração dos defic ientes.

Arryanne Queiroz Delegada de Polícia Federal no DF e pesquisadora do Instituto de Bioética Direitos Humanos e Gênero (ANIS) 